\title{
Analysis of Symptom Development in Relation to Quantity of Rice stripe virus in Rice (Oryza sativa) to Simplify Evaluation of Resistance
}

\author{
Mitsuru Okuda, ${ }^{1, \dagger}$ Takuya Shiba, ${ }^{1}$ Masahiro Hirae, ${ }^{1}$ Akira Masunaka, ${ }^{2}$ and Minoru Takeshita ${ }^{3}$ \\ ${ }^{1}$ Central Region Agricultural Research Center, NARO, 2-1-18 Kannondai, Tsukuba, Ibaraki 305-8666, Japan; ${ }^{2}$ Western Region Agricultural \\ Research Center, NARO, 6-12-1 Nishifukatsu-cho, Fukuyama-shi, Hiroshima 721-8514, Japan; and ${ }^{3}$ Faculty of Agriculture, University of \\ Miyazaki, Gakuen-kibanadai-nishi-1-1, Miyazaki, 889-2192, Japan \\ Accepted for publication 10 October 2018.
}

\begin{abstract}
Rice stripe virus (RSV) is one of the most devastating pathogens of rice (Oryza sativa) in rice-growing regions of East Asia. We analyzed the increase in RSV accumulation in infected rice plants over time and evaluated the association between disease severity and RSV accumulation with the aim of establishing an experimental system for accurate and efficient evaluation of RSV resistance in rice. As an index of RSV accumulation in plants, relative concentration of RNA corresponding to the coat protein gene region was measured using reverse-transcription quantitative polymerase chain reaction. Actin and elongation factor $1 a$ were used as the host reference genes. RSV concentrations tended to increase with time from 7 to 28 days after inoculation, and a strong positive correlation was observed between the $\log$ RSV concentrations in the midsections of the uppermost leaves and in

the stems at the first leaf sheath position. We analyzed RSV concentrations at these two locations 21 days after inoculation with RSV and assessed severity of disease symptoms based on a commonly used scale (Washio's six-grade scale) rated as A (most severe), B, Bt, C, Cr, or D (mild symptoms). RSV concentrations at both locations were high in plants graded $\mathrm{A}, \mathrm{B}$, or Bt, with no significant difference in concentration of RSV among the three grades, but concentrations were significantly higher in the three grades compared with that in the plants in grade D. RSV concentrations were highly variable among plants in grades $\mathrm{C}$ and $\mathrm{Cr}$. On the basis of these data, we propose a new formula to estimate the range of disease severities with greater ease and practical value. The values calculated by the new formula corresponded well to those based on Washio's six-grade scale.
\end{abstract}

Rice stripe disease is one of the most devastating viral diseases of rice (Oryza sativa L.) in East Asia, including Japan, South Korea, and China (Hibino 1996; Shiba et al. 2018; Wang et al. 2008). The causal virus, Rice stripe virus (RSV), belongs to the genus Tenuivirus (Shirako et al. 2011). RSV is persistently transmitted by the small brown planthopper (SBPH) (Laodelphax striatellus (Fallen)) to rice plants and is transovarially transmitted from adult SBPHs to offspring (Hibino 1996). In Japan, although outbreaks of rice stripe disease caused severe damage from the 1960s to the 1980 s, outbreaks gradually decreased in the late 1980s owing to increased use of RSV-resistant rice cultivars and pesticides to control SBPHs; the incidence was negligible by the early 2000 s. However, since 2004, the disease has spread rapidly in some prefectures in the Kanto, Kinki, and Kyushu regions (Shiba et al. 2016; Yoshida et al. 2014). Extensive outbreaks have been reported in China and South Korea (Kim et al. 2011; Wang et al. 2008). Although the reasons for the recent epidemics in East Asia remain unclear, the suspected contributing factors include the development of pesticide resistance in the insect vector (Sanada-Morimura et al. 2011), climate change (Yamamura and Yokozawa 2002), and changes in cultivation practices.

RSV causes chlorotic stripes, mottling, and necrotic streaks on the leaves and often kills the whole plant if a young seedling is infected. Panicles of severely diseased plants are often sterile, resulting in lower yield (Hibino 1990). Washio et al. (1967) reported

†Corresponding author: M. Okuda; mokuda@affrc.go.jp

Funding: This work was supported by the Japan Society for the Promotion of Science KAKENHI grant number $16 \mathrm{H} 04887$.

*The $\boldsymbol{e}$-Xtra logo stands for "electronic extra" and indicates that three supplementary figures are published online.

The author(s) declare no conflict of interest.

(c) 2019 The American Phytopathological Society the existence of many resistant cultivars of both Japanese upland rice, which are grown in dry fields, and also cultivars of indica-type rice. Although many resistant cultivars, including Asahino-yume, have been developed by introducing the $S t v-b^{i}$ gene (Izawa et al. 2001) from the indica rice cultivar Modan, major Japanese cultivars such as Koshihikari are susceptible to RSV.

In Japan, the acreage of forage rice has been increasing as a way to use fallow fields and to improve food self-sufficiency (Kato 2008). To reduce production costs in cultivation of forage rice, pesticide use is often reduced, and special cultivars resistant to various pests and diseases are used. Yumeaoba and Takanari, which are resistant to rice stripe disease, are examples of such cultivars. However, the genetic origin of resistance genes introduced into many of cultivars of forage rice is uncertain, and the degree of their resistance is unknown.

In Japanese RSV-resistance breeding programs, resistant cultivars are screened by inoculating plants with RSV using SBPHs and assessing symptom development. Standard practice consists of rating individual plants on the basis of a six-grade, qualitative scale proposed by Washio et al. (1967), which ranks disease severity as A (most severe), B, Bt, C, Cr, or D (mild), and calculating a diseaserating index from the number of plants assessed in each grade. However, skill and experience are required to assess disease severity from symptoms alone in cultivars with diverse symptom phenotypes. Even resistant cultivars carrying the $S t v-b^{i}$ gene succumb to $\mathrm{RSV}$ if infection pressure is high, and can become virus acquisition sources for SBPHs when RSV replicates within the infected plants (Noda et al. 1991). Thus, a quantitative method to evaluate resistance on the basis of viral replication in plants would be valuable. Several methods have been developed to detect RSV in plants (Uehara-Ichiki et al. 2013). Enzyme-linked immunosorbent assay (ELISA) is one of the most commonly used methods because it is cheap, whereas the major advantages of reverse-transcription quantitative polymerase chain reaction (RT-qPCR) are sensitivity and linearity of quantification (Zhang et al. 2008).

In this study, we analyzed the accumulation of RSV in infected rice plants over time and evaluated the correlation between disease 
severity and RSV accumulation with the aim of establishing an experimental system for accurate and efficient evaluation of resistance to $\mathrm{RSV}$ in rice.

\section{MATERIALS AND METHODS}

Virus and vector populations. A population of SBPHs carrying RSV was collected from rice plants with typical symptoms of rice stripe disease in Ibaraki Prefecture, Japan (Okuda et al. 2017). The population was bred in insect cages $(340$ by 260 by $340 \mathrm{~mm}$; Sanshin Industrial, Kanagawa, Japan) at $25^{\circ} \mathrm{C}$ with a 16 -h photoperiod and a diet of young rice seedlings (Koshihikari). To increase the number of viruliferous individuals, RSV-viruliferous females were selected according to Okuda et al. (2017). Their offspring were used in inoculation trials. The incidence of viruliferous SBPHs in the population was estimated using a simplified ELISA (Takahashi et al. 1987) and ranged from 38 to $57 \%$.

Inoculation trials. Seed of rice (Koshihikari) were soaked in tap water at $25^{\circ} \mathrm{C}$ for 7 days and sown in 8 -cm pots containing rice nursery soil ( 25 seeds/pot). After germination, seedlings were thinned to 20 vigorous plants per pot and grown for 7 days up to the first- to second-leaf stage. The potted plants were placed in insect cages with second- to fourth-instar larvae of the previously described population of SBPHs ( $n=5$ per plant). All plants in each experiment were inoculated using larvae from the same cage. After 5 days, the insects were killed by spraying $1.5 \%$ clothianidin, and the seedlings were grown at 25 to $30^{\circ} \mathrm{C}$ under natural light in a greenhouse. The day the insects were killed was considered day 0 .

Symptom severity of RSV was based on the scale developed by Washio et al. (1967), where A = plants extremely stunted with part or all of affected leaves dead; B = plants extremely stunted but with affected leaves alive; $\mathrm{Bt}=$ plants growing fairly well but otherwise similar to $\mathrm{B} ; \mathrm{C}=$ plants growing well but with welldefined, scattered punctate, or sometimes pale yellow streak lesions; $\mathrm{Cr}=$ similar to $\mathrm{C}$ but with affected leaves being rolled to some extent; and $\mathrm{D}=$ plants growing vigorously with only slight symptoms.

RSV quantification. As an index of RSV accumulation in rice plants, the relative concentration of RNA corresponding to the RSV coat protein $(C P)$ gene region in RSV RNA3 (Zhu et al. 1991) was quantified by RT-qPCR. To detect the RSV CP region, the CP-F and CP-R primers were used (Li et al. 2012) (Table 1). Rice genes encoding 1-tubulin, actin, 18S ribosomal RNA (rRNA), elongation factor 1a (EF-1a), and ubiquitin were evaluated as candidate host reference genes for relative quantification of RSV. Primers reported by Kim et al. (2003) were used to amplify the 1-tubulin, 18S rRNA, and actin genes. Primers to amplify the $E F-1 a$ and ubiquitin genes were newly designed (Table 1) on the basis of nucleotide sequences obtained from GenBank (accession numbers X16280 and AK061988, respectively) by using Geneious R8 (Biomatters, Auckland, New Zealand).

RT-qPCR was performed on a LightCycler 96 system (Roche, Mannheim, Germany) using RNA direct SYBR qPCR Mix
(Toyobo, Tokyo, Japan). The PCR conditions consisted of RT at $61^{\circ} \mathrm{C}$ for $20 \mathrm{~min}$ and denaturation at $95^{\circ} \mathrm{C}$ for $30 \mathrm{~s}$, followed by 40 amplification cycles $\left(95^{\circ} \mathrm{C}\right.$ for $15 \mathrm{~s}, 55^{\circ} \mathrm{C}$ for $15 \mathrm{~s}$, and $72^{\circ} \mathrm{C}$ for 30 s). At the end of each cycle, the intensity of fluorescence generated by SYBR Green I (wavelength $=497 \mathrm{~nm}$ ) was measured, and the cycle threshold $(\mathrm{Ct})$ was calculated using software installed on the LightCycler 96. The assay was performed in duplicate for each sample, and samples were retested if the two $\mathrm{Ct}$ values differed by 0.4 or more.

In the first step, the amplification efficiency for each primer was determined by preparing fivefold serial dilutions $(100,20,4,0.8$, 0.16 , and $0.032 \mathrm{ng} / \mu \mathrm{l}$ ) of RNA extracted from RSV-infected rice plants with disease severity grade B. PCR efficiency was calculated for each primer on the basis of the derived regression between RNA concentrations and $\mathrm{Ct}$ values for each RNA dilution series. An RNA sample from a healthy rice plant was used as a negative control. In the second step, RT-qPCR was performed using each primer set with RNA samples extracted from leaves and the stem at the first leaf sheath (FLS) of $24 \mathrm{RSV}$-infected plants (4 plants for each grade of disease severity $\mathrm{A}, \mathrm{Bt}, \mathrm{B}, \mathrm{C}, \mathrm{Cr}$, or $\mathrm{D})$. The resultant $\mathrm{Ct}$ values were analyzed using NormFinder (Andersen et al. 2004) and BestKeeper (Pfaffl et al. 2004). Stably expressed host genes with high PCR efficiency were selected as reference genes. On the basis of these results, the $\mathrm{Ct}$ values of RSV CP and reference genes were calculated for each of the samples described below, and relative viral concentration was calculated by using the comparative $\mathrm{Ct}$ method (Livak and Schmittgen 2001). An RNA sample (100 ng/ $\mu \mathrm{l})$ extracted from an RSV-infected rice plant with disease severity grade $\mathrm{B}$ was used as a reference sample for the comparative $\mathrm{Ct}$ method. The reference RNA sample was used in each PCR assay.

Selection of plant tissue for viral quantification. Seedlings of Koshihikari were used to determine the best tissue to sample for quantifying RSV in infected rice. Plants were inoculated with RSV as described above. On days $6,14,18$, and 35, approximately $1-\mathrm{cm}$ sections were excised from the middle portions of all developed leaves except the first true leaf, and from stems at FLSs (Fig. 1) of three plants on each sample day, and placed in homogenizing tubes containing 3-mm zirconia beads. After adding $400 \mu \mathrm{l}$ of Isogen (Nippon Gene, Toyama, Japan), the samples were homogenized using a Multi-Beads Shocker (Yasui Kikai Corp., Osaka, Japan). RNA was extracted according to the standard protocol in the manual for Isogen and subjected to RT-qPCR.

Concentration of RSV, disease severity, and time after inoculation. Seedlings of Koshihikari were inoculated as described above. On days 7, 14, 21, and 28, approximately 1-cm segments were excised from the middle portions of the uppermost leaves and from stems at FLSs (Fig. 1) from 20 plants on each sample day. RNA was extracted as described above and subjected to RT-qPCR. A different set of rice plants was inoculated with RSV and rated for disease severity 3 weeks after inoculation using the scale developed by Washio et al. (1967). RNA was extracted from approximately $1-\mathrm{cm}$ segments that were excised from the middle

TABLE 1. Oligonucleotide primers used in this study in conjunction with a quantitative polymerase chain reaction to quantify Rice stripe virus (RSV) in infected plant tissue samples

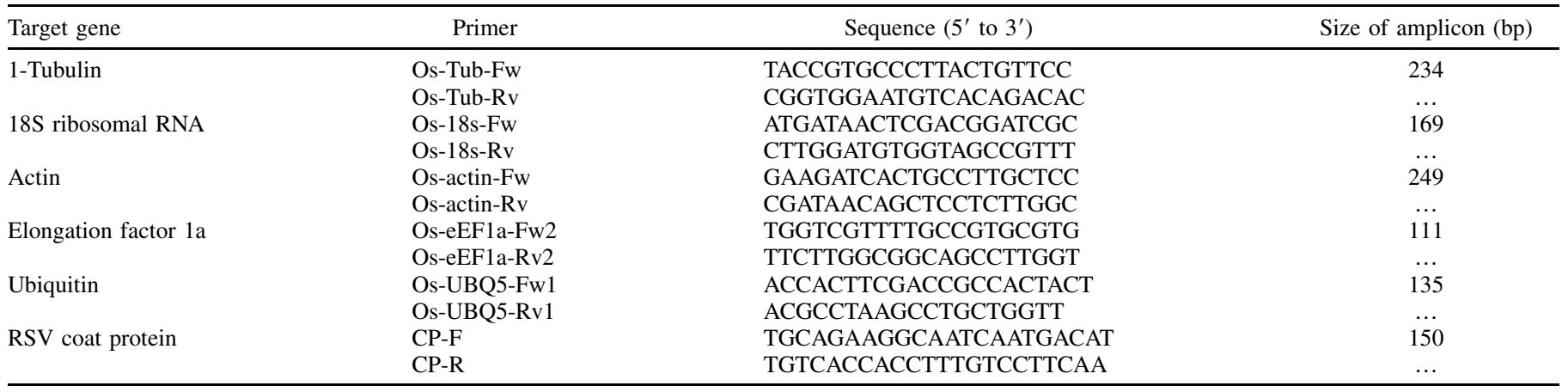


portions of the uppermost leaves and from stems at FLSs from six plants for each disease severity grade, and was subjected to RT-qPCR.

Development of a new disease severity index. Seedlings of Koshihikari Asahino-yume, harboring the rice stripe disease resistance gene $s t v-b^{i}$ (Izawa et al. 2001), and near-isogenic lines of Koshihikari, harboring the rice stripe disease resistance genes stva (NIL-STV2), stvb (NIL-STV11), and both stva and stvb (NILSTV2/STV11) (Maeda et al. 2006), were inoculated with RSV as described above. Three weeks after inoculation, each plant was rated for disease severity based on the Washio six-grade scale, and the disease severity index was calculated as follow (Washio et al. 1967):

Disease rating index $(\mathrm{DRI})=(100 \mathrm{~A}+80 \mathrm{~B}+60 \mathrm{Bt}+40 \mathrm{Cr}+$

$$
20 \mathrm{C}+5 \mathrm{D}) / N
$$

where A, B, Bt, Cr, C, and D are numbers of seedlings with the respective grades and $N$ is the total number of seedlings.

According to the correlation between the concentration of virus detected in the rice plants and the symptoms assessed on those plants as described in the results, the following simplified formula was developed:

$$
\text { Simple disease index }(\mathrm{SDI})=\left(80 \times N_{\mathrm{A}}+35 \times N_{\mathrm{B}}\right) / N
$$

where $N_{\mathrm{A}}$ is the number of dead or extremely stunted plants (ratings $\mathrm{A}, \mathrm{B}$, and Bt on Washio's scale); $N_{\mathrm{B}}$ is the total number of plants with pale yellow, scattered punctate, or streak lesions on the leaves

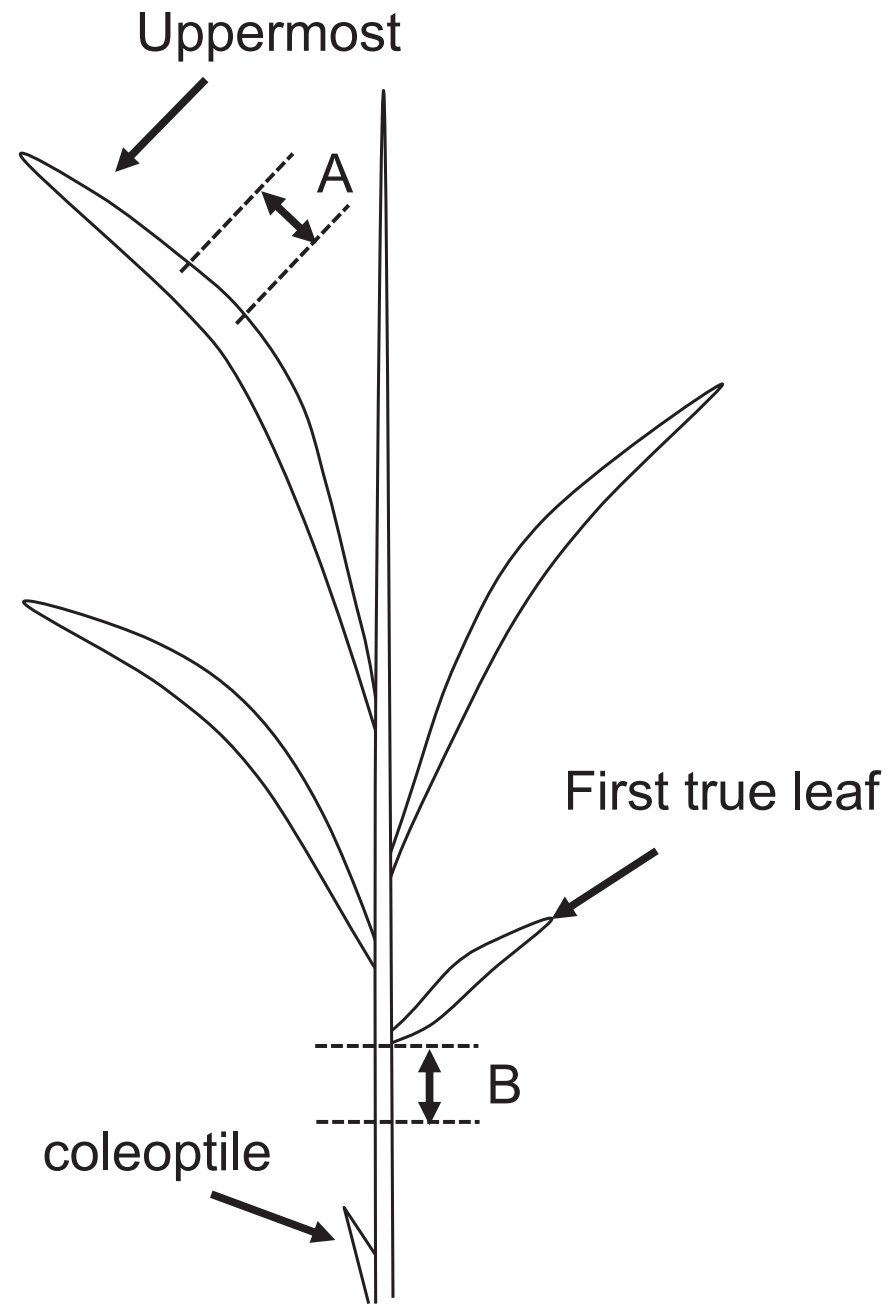

Fig. 1. Tissue sample types for RNA extraction from Rice stripe virus-infected rice plants. A, Uppermost midleaf section; B, stem at the first leaf sheath. Uppermost means the youngest expanded leaf. (ratings $\mathrm{C}$ and $\mathrm{Cr}$ on Washio's scale); and $N$ is the total number of plants. Washio's grade D plants were not regarded as diseased plants but were included in the total number of plants. The coefficient values in the SDI formula were adjusted to be close to that of the DRI.

Statistical analyses. Statistical analyses were performed using either Prism 7 for Mac OS X (Graph Pad Software, La Jolla, CA, U.S.A.) or JMP13 (SAS, Cary, NC, U.S.A.). The association between concentration of RSV and the number of days after inoculation was investigated by correlation analysis using the log-transformed values for concentration of RSV in the uppermost leaves or the stems at FLS of the same plants. Pearson's correlation analysis was used to evaluate the association between the log-transformed concentrations of RSV in the top leaves and in the stems at FLS of the same plant. Correlation analysis and linear regression were performed to determine the association and relationship, respectively, between the log-transformed RSV concentrations in the top leaves and in the stems at FLS. The log-transformed concentrations of RSV at each disease severity rating were compared by analysis of variance. A post hoc Tukey-Kramer honestly significant difference test was used to compare the means $(\alpha=0.05)$.

\section{RESULTS}

Identification of host genes suitable for viral quantification. Serial dilutions of all RNA samples extracted from RSV-infected rice plants showed RSV CP-specific amplification, which allowed calculation of $\mathrm{Ct}$ values. For RNA samples $(100 \mathrm{ng} / \mu \mathrm{l})$ extracted from healthy plants, the $\mathrm{Ct}$ value was $\geq 38$ or could not be calculated. A linear relationship was found between the log of the RNA concentration and the $\mathrm{Ct}$ value (data not shown). PCR efficiency for RSV CP was calculated to be $100.3 \%$. The amplification efficiency of host gene regions was $104.9 \%$ for 1 -tubulin, $80.9 \%$ for $18 S$ rRNA, $96.8 \%$ for actin, $93.8 \%$ for the EF-1a gene, and $98.4 \%$ for ubiquitin.

BestKeeper analysis of the $\mathrm{Ct}$ values for 24 plants with ratings of disease severity showed a strong association for the $18 S$ rRNA and actin genes (Table 2); thus, the expression of these two genes was considered highly stable. NormFinder analysis of the $\mathrm{Ct}$ values identified the actin gene as having the lowest value and, thus, as being the most stable. The $18 S r R N A$ and $E F-1 a$ genes ranked next in stability (Table 2). The $18 S$ rRNA gene was expressed at extremely high levels, necessitating dilution of RNA samples to obtain stable $\mathrm{Ct}$ values. Therefore, actin and EF-1a genes were selected as reference genes.

Selection of plant tissue for viral quantification. The relative concentration of RSV in various plant parts $6,14,18$, and 35 days after RSV-inoculation (dai) was determined using the actin gene RNA as a reference. The number of leaves of the plants at 6,14 , 18 , and 35 dai was $2,3,4$, and 5, respectively. Due to RSV infection, the growth of the plants was visibly delayed compared with that of healthy plants. Although the sample size was small, concentrations of RSV in the stems at FLS tended to increase with the number of days after inoculation (Fig. 2A). Although the concentration of RSV

TABLE 2. Stability values of candidate reference genes used to quantify rice stripe virus in diseased tissues from rice plants

\begin{tabular}{lcc}
\hline Gene & Coefficient of correlation $^{\mathrm{a}}$ & Stability value $^{\mathrm{b}}$ \\
\hline 1-Tubulin & $0.74(0.001)$ & 0.400 \\
18s ribosomal RNA & $0.86(0.001)$ & 0.163 \\
Actin & $0.84(0.001)$ & 0.074 \\
Elongation factor 1a & $0.71(0.001)$ & 0.175 \\
Ubiquitin & $0.68(0.001)$ & 0.202 \\
\hline
\end{tabular}

a Calculated using BestKeeper. A gene with a higher value is more stable. The $P$ values are shown in parentheses.

b Calculated using NormFinder. A gene with a lower stability value is more stable. 
in leaves at the same position but different days after inoculation was highly variable, those in the top leaves tended to increase with days after inoculation (Fig. 2B). Similar results were obtained from RSV quantification using the $E F-1 a$ gene as a reference (data not shown). Accordingly, the stem at FLS and the uppermost leaf were selected as the sampling locations and used for RSV quantification in all subsequent experiments.

Concentration of RSV, disease severity, and time after inoculation. Relative concentration of RSV was determined 7, 14, 21 , and 28 dai using the actin gene as a reference. On all sampling days, viral concentrations in both regions showed substantial interindividual variability, with the greatest difference between the lowest and highest concentrations on day 7 (Fig. 3). In the stems at FLS and the uppermost leaves, concentrations of RSV tended to increase with the number of days after inoculation (Fig. 3). Concentrations of RSV tended to change in a similar manner at both sample locations in the same plant (Fig. 4), resulting in a positive correlation between the log RSV concentrations in the two locations (Pearson's correlation coefficient, $r=0.8734, P<0.0001$ ). The coefficient of determination $\left(r^{2}=0.7628\right)$ for the linear regression indicated a good linear relationship between the concentrations at both sampled locations. The slope of the linear regression was close to $1(1.01 \pm 0.06778)$, which indicates that RSV concentrations at the two sample locations increase proportionally. Similar results were obtained when $E F-l a$ was used as a reference (Supplementary Figs. S1 and S2) (Pearson's correlation coefficient, $r=0.886, P<0.0001$; linear regression, $r^{2}=0.7849$ ).

Relationship of RSV concentration to disease severity. Concentration of RSV was determined using the actin gene as a reference in RSV-infected plants grouped into six categories according to disease severity (Washio et al. 1967). Concentrations of RSV were high in both the stems at FLS and the uppermost leaves of plants rated $\mathrm{A}, \mathrm{B}$, or $\mathrm{Bt}$, with no significant differences in the mean concentration of RSV among these groups (Fig. 5). Concentration of RSV in plants rated $\mathrm{C}$ showed the greatest interindividual variability, with some plants having high concentrations similar to those in plants rated $\mathrm{A}, \mathrm{B}$, or $\mathrm{Bt}$ and others having low concentrations similar to those in plants rated D. Plants rated $\mathrm{Cr}$ had concentrations of RSV similar to those in plants rated C. Concentrations of RSV were consistently low in plants rated D, and the mean concentration of RSV in this group was significantly lower compared with those in plants rated A, B, or Bt (Fig. 5). There was a strong positive correlation between the log RSV concentrations in the stem at FLS and the uppermost leaf of each plant (Fig. 6) (Pearson's correlation, $r=0.9168, P<0.0001$ ). Regression analysis demonstrated a strong linear relationship for concentration between the two sampled locations on the plants $\left(r^{2}=0.8405\right)$.

Development of the new disease severity index. The susceptible cultivar Koshihikari showed the most severe damage among the cultivars tested, whereas the resistant cultivar Asahinoyume and the near-isogenic lines (except NIL-STV11, harboring the $s t v b$ gene) showed moderate resistance to infection with RSV. NIL-STV11 was susceptible in this assay. The values of the SDI for each rice cultivar were numerically very similar to those of the DRI (Table 3).

\section{DISCUSSION}

To determine the accumulation of RSV in rice plants, we quantified the relative concentration of RNA corresponding to the RSV $C P$ gene region by RT-qPCR. The expression of the $C P$ gene, which is directly related to the formation of viral particles, is widely used to quantify virus accumulation in plants, including several gramineous viruses; for example, Southern rice black-streaked $d$ warf virus in rice (Li et al. 2014). Among these genes, NS3, which is a gene-silencing suppressor and is considered to be involved in symptom development (Xiong et al. 2009), may warrant further investigation and offer a new perspective for evaluating resistance to RSV.
A

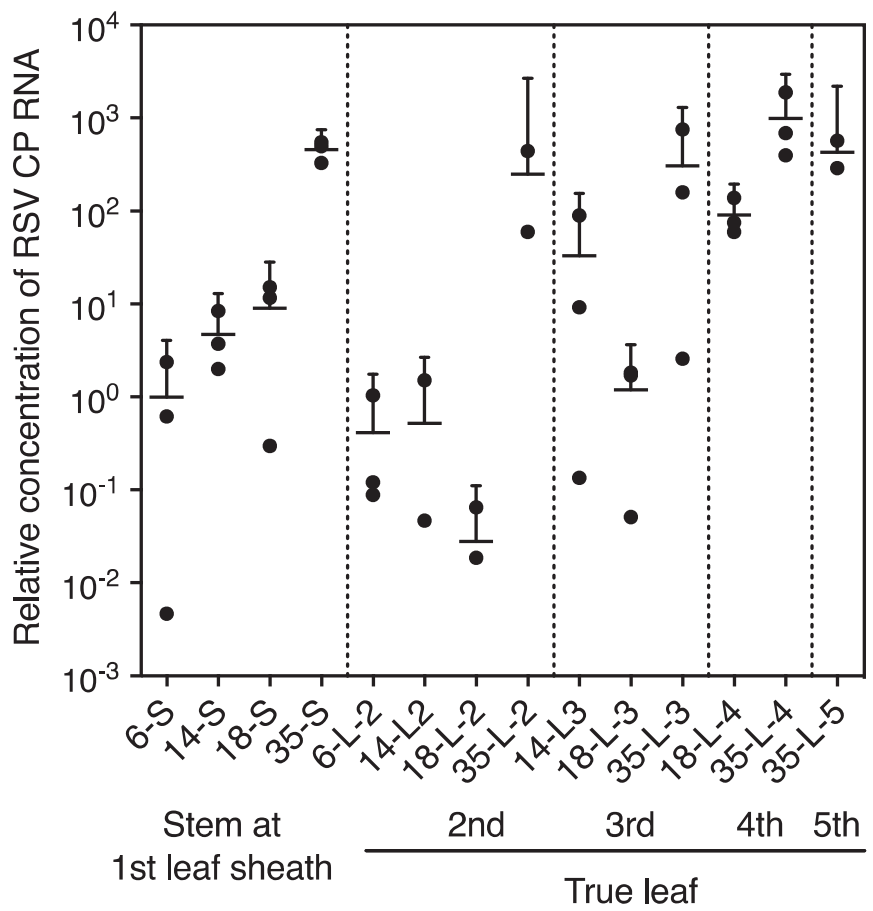

B

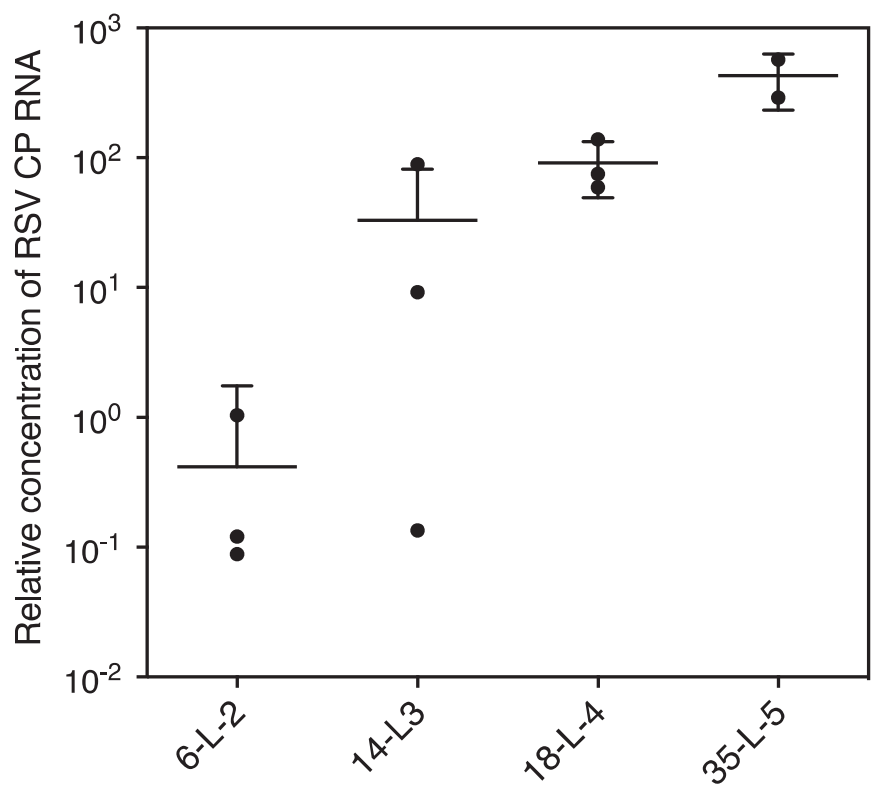

Uppermost leaves

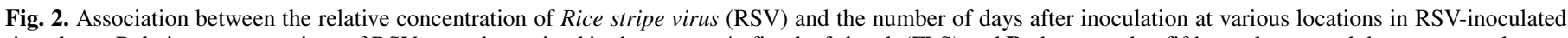

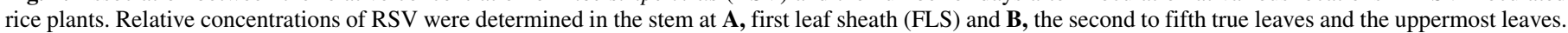

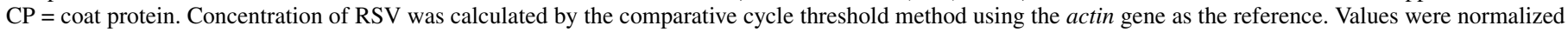

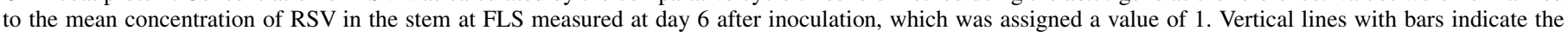

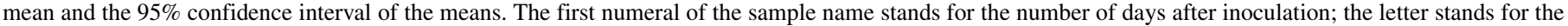
stem at FLS (S) or leaf (L), and the numeral after "L" stands for the leaf position, with the lowest position being 1. 
Relative RNA quantification by RT-qPCR requires selection of housekeeping genes suitable for the targeted tissues and physiological states of the host (Kozera and Rapacz 2013). We selected actin and EF-1 $a$ from among five rice housekeeping genes and used them as reference genes for the relative quantification of RSV. These genes have previously been used as reference genes. Fang et al. (2015) assessed the stability of candidate reference genes in rice plants infected with RSV or Rice black-streaked dwarf virus and recommended a combination of $U B Q 10$ and GAPDH as the most suitable reference genes. NormFinder analysis by Fang et al. (2015) showed that actin and EF-la had stability values similar to those of $U B Q 10$ and $G A P D H$. Our data confirm the high stability of actin and $E F-1 a$ among rice plants exhibiting a range in severity of symptoms associated with infection by RSV.

The preliminary analysis showed that the concentration of RSV tended to increase with time in the uppermost leaf. The more detailed analysis, in which RSV concentration was measured at 7day intervals, showed a clear tendency for the viral concentration to increase with time in the uppermost leaf and the stem at FLS. After infection via SBPH, RSV is translocated through the vascular system to the meristem (Sonku and Sakurai 1973). Rapid replication of RSV in young meristems (Sonku and Sakurai 1973) may explain the increase in viral concentration in the uppermost leaf with time. Samples collected from the stem at FLS also contained meristem material, which may explain the association in RSV concentration in the stem at FLS and the uppermost leaf. Thus, we consider that both tissue types are suitable to evaluate the resistance of rice cultivars to RSV. However, there is greater ease in sampling the stem at FLS because it is a more clearly defined sample point. The drawback is that sampling the stem at FLS kills the entire plant, whereas uppermost-leaf sampling allows continuous analysis of the same plant. Therefore, the stems at FLS are suitable for quantification on a fixed date, and the uppermost leaves are more suitable to analyze the changes in accumulation level of RSV in the same plants where temporal sampling may be required.

Although RSV is transmissible to Nicotiana benthamiana by mechanical inoculation with RSV-infected rice sap (Xiong et al.
2008), its transmission to rice is possible only by the insect vector, SBPH. Not all of the SBPHs used in this study were viruliferous, and larval preference could not be made completely uniform; therefore, the number of viruliferous insects per plant could not be adjusted precisely. Rice plants with shorter duration of growth after germination are more susceptible to RSV and exhibit earlier disease

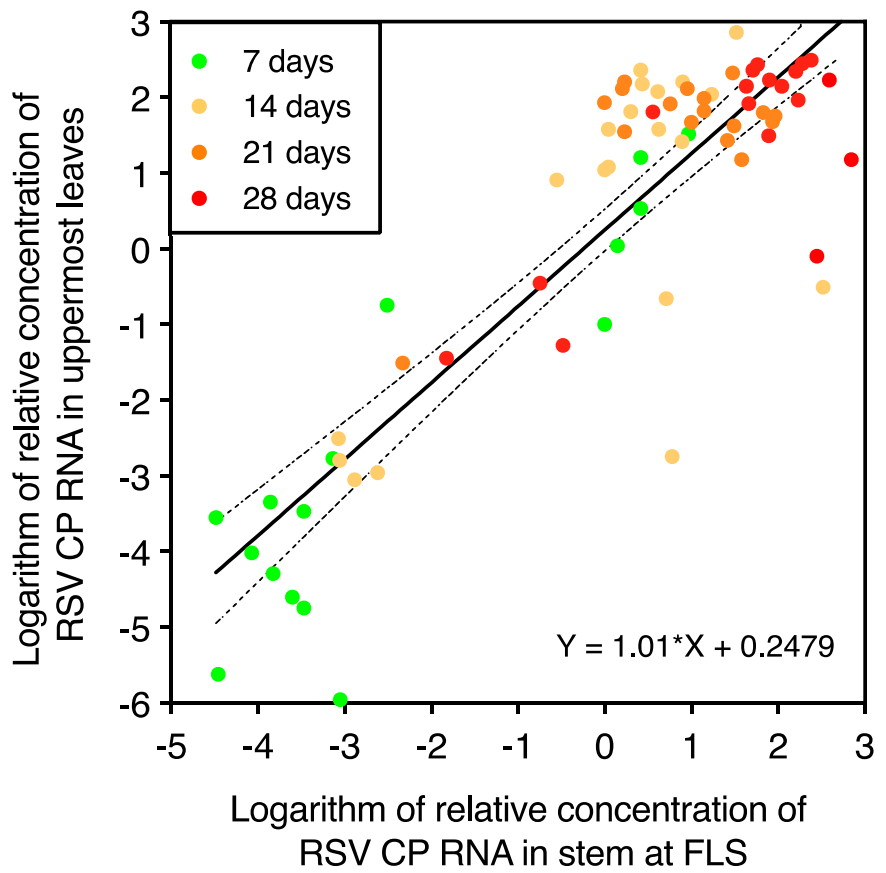

Fig. 4. Scatter plot showing the association between relative concentration of Rice stripe virus (RSV) in the stem at first leaf sheath and in the uppermost leaf of rice plants at different time points after RSV inoculation. $\mathrm{CP}=$ coat protein. The solid line shows the linear regression line whose equation is shown on the graph ( $\mathrm{x}$ and $\mathrm{y}$ are horizontal and vertical coordinates, respectively). Dotted lines are the $95 \%$ confidence limits of the best-fit line.
A

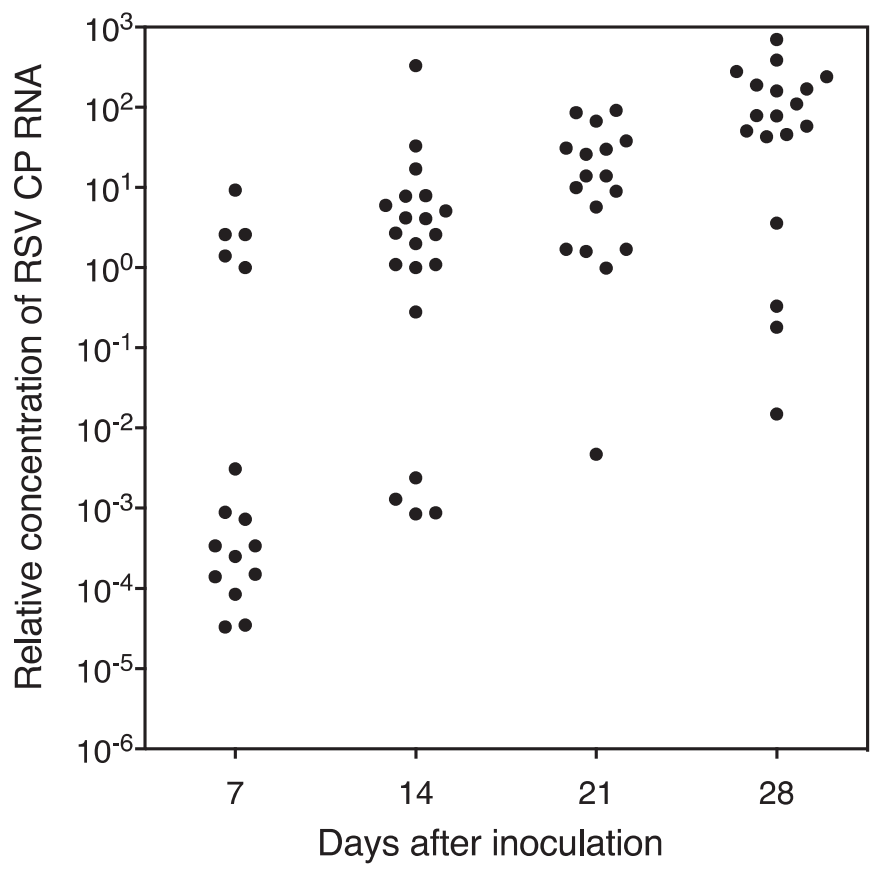

B

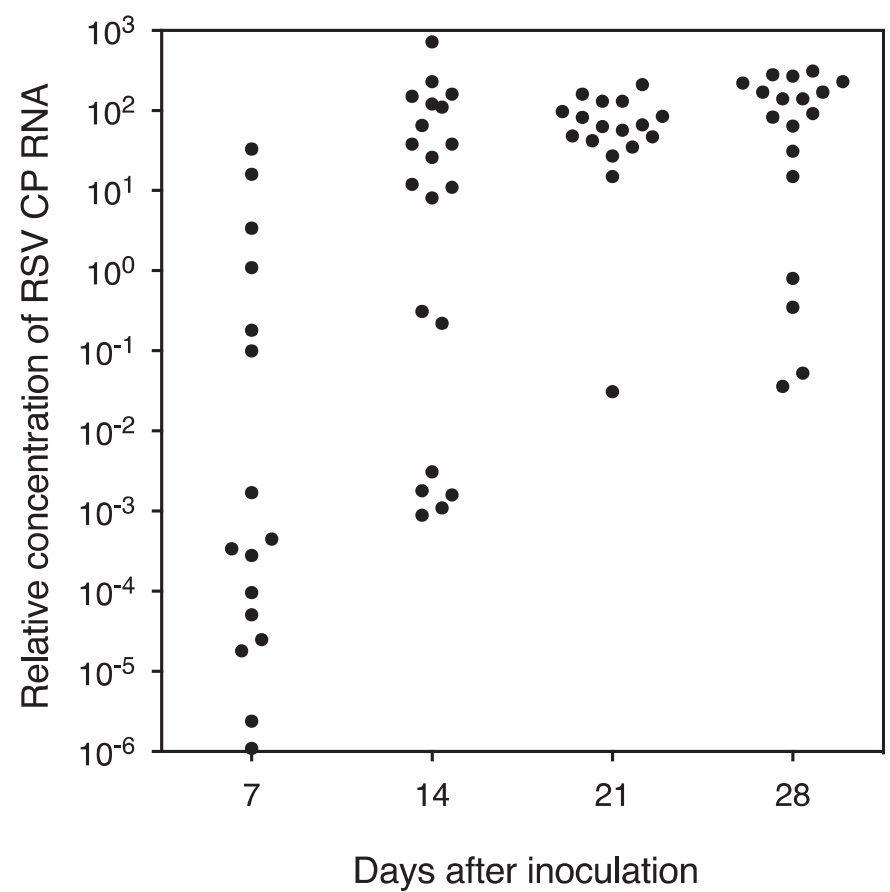

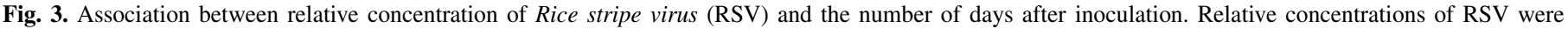

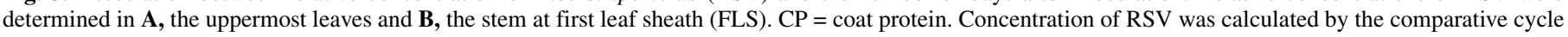

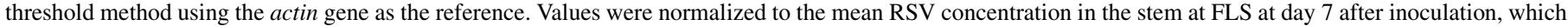
was assigned a value of 1 . 
onset (Yamada and Yamamoto 1955). Given these factors, differences in inoculum levels of RSV introduced into each rice plant might contribute to the interindividual variability observed in concentration of RSV. Further studies are needed to understand the effect of the number of viruliferous SBPH feeding on rice plants and inoculation access period on RSV replication.

At 7 dai, the plants had few observable symptoms but $30 \%$ of them had relatively high viral concentrations. The interindividual variability in viral concentration was greatest at this point. From 14 dai onward, readily observable symptoms were evident, and more
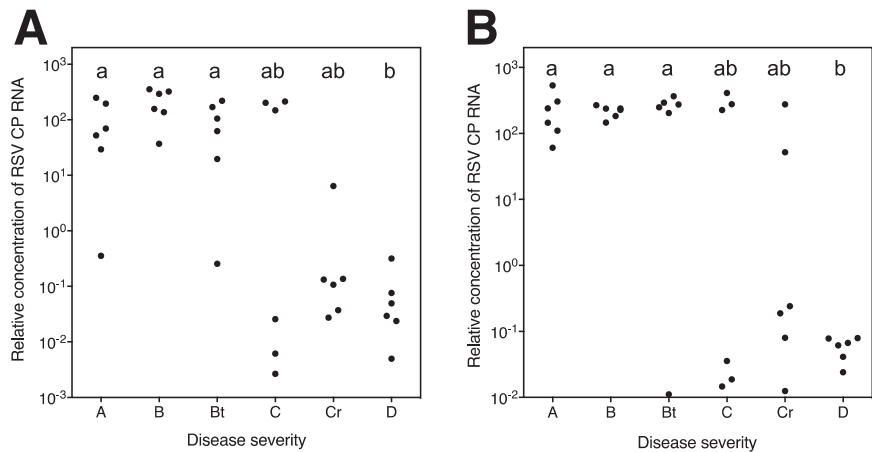

Fig. 5. Association between disease severity and relative concentration of Rice stripe virus (RSV). Relative concentrations of RSV at day 21 after inoculation with RSV were determined in $\mathbf{A}$, the uppermost leaf and $\mathbf{B}$, the stem at first leaf sheath. $\mathrm{CP}=$ coat protein. Disease severity was assessed using the severity scale developed by Washio et al. (1967). Concentration of RSV was calculated by the comparative cycle threshold method using the actin gene as the reference. Values were normalized to the mean concentration of RSV in the uppermost leaf of plants rated A, which was assigned a value of $10^{2}$. Different lowercase letters at the top of each panel indicate significant differences between means (based on a Tukey-Kramer honestly significant difference means separation, $\alpha=0.05)$.

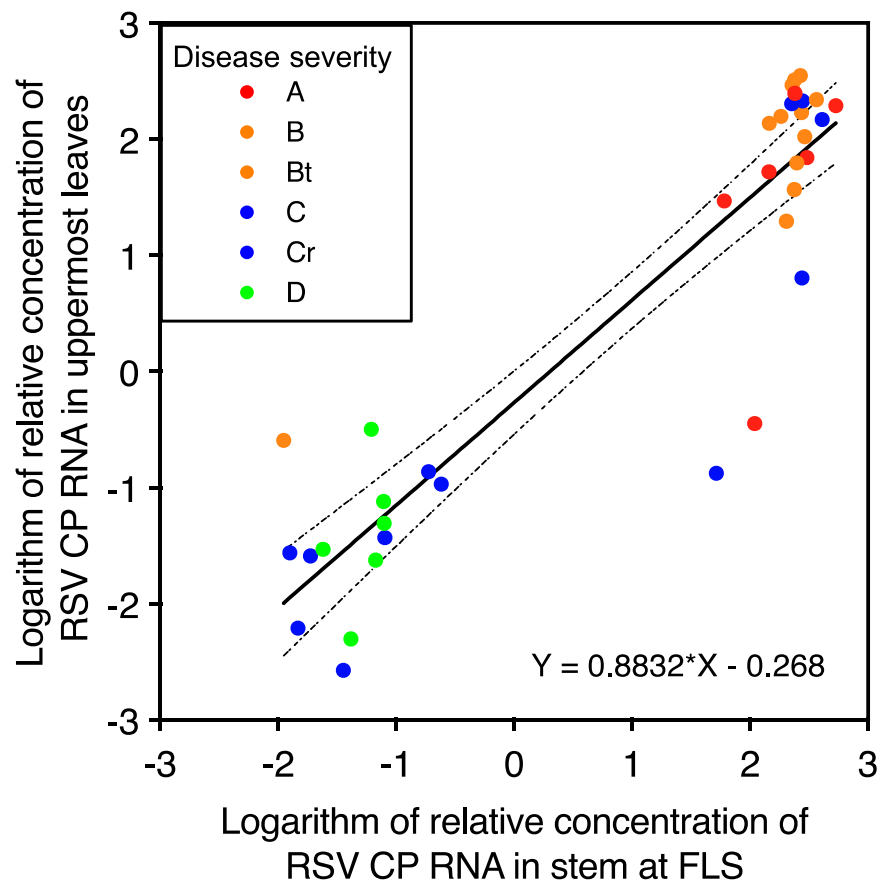

Fig. 6. Scatter plot showing the association between relative concentration of Rice stripe virus (RSV) in the stem at first leaf sheath and in the uppermost leaf of rice plants at day 21 after inoculation with RSV. CP = coat protein. A, $\mathrm{B}, \mathrm{Bt}, \mathrm{C}, \mathrm{Cr}$, and $\mathrm{D}$ indicate grade of disease severity using the severity scale developed by Washio et al. (1967). The solid line shows the linear regression line whose equation is shown on the graph ( $\mathrm{x}$ and $\mathrm{y}$ are horizontal and vertical coordinates, respectively). The dotted lines are the $95 \%$ confidence intervals of the best-fit line. than $70 \%$ of the plants had relatively high viral concentrations. In both the uppermost leaf and the stem at FLS, the minimum concentration of RSV increased with time. Disease severity was marked by substantial interindividual variability, and some plants had few observable symptoms, even at 28 dai. However, these symptom-free plants were infected with RSV, albeit at low concentrations. Previous studies have demonstrated that the expression levels of various genes change in RSV-infected rice plants. The transcription factors mediating host resistance (for example, WRKY) (Shimono et al. 2007) are not induced at early stages of infection but are induced only when overt symptoms develop (Satoh et al. 2010). Magnesium chelatase and aspartic proteases are involved in RSV-induced chlorosis and plant death (Wang et al. 2015). Analysis of the differences in gene expression among plants with various symptom severities may help clarify the molecular mechanisms of RSV resistance and host responses related to symptom development.

The resistance gene $S t v-b^{i}$, derived from the indica cultivar Modan (Washio et al. 1967), has been introduced into many commercial cultivars in Japan. Under high infection pressure of RSV, cultivars carrying $S t v-b^{i}$ are susceptible to infection by RSV and can become virus sources for SBPHs (Noda et al. 1991). SBPHs do not acquire RSV from symptomless plants or plants with lower viral concentration (Ishii 1971). In our study, plants rated as grade D did not exhibit clear symptoms and had low concentrations of RSV; therefore, they are unlikely to be an inoculum source of RSV for SBPHs. In further analysis, we need to determine the threshold viral concentration for acquisition by SBPHs from RSV-infected plants. Although many other resistance genes have been identified (Cho et al. 2013), they have been selected on the basis of observed symptoms without taking into account viral concentrations, and their effect on RSV replication is unclear. If a plant does not exhibit any symptoms despite carrying a high titer of RSV, it may be an inoculum source of the virus. Selected resistant cultivars should be checked for presence of the virus by RT-qPCR before putting them into practical use even if they do not exhibit any symptoms.

Several genes for resistance to rice stripe disease have been identified by quantitative trait locus (QTL) analysis (Maeda et al. 2004; Zhang et al. 2010). In many of these studies, the disease severity scale proposed by Washio et al. (1967) was used to evaluate the germplasm. However, Washio's formula requires distinguishing between scales $\mathrm{B}$ and $\mathrm{Bt}$, or $\mathrm{C}$ and $\mathrm{Cr}$, which can be ambiguous in some cases. In the present study, we found no significant difference in concentration of RSV among plants rated A, B, or Bt. Therefore, we conclude that these plants should be treated as equivalent in terms of viral replication. Concentrations of RSV in plants rated $\mathrm{C}$ and $\mathrm{Cr}$ were high but variable and showed a similar trend. We believe that grade $\mathrm{D}$ can be eliminated because these plants had mild symptoms and significantly lower concentrations of RSV compared with A, B, or Bt. We propose an alternative, simplified formula to facilitate evaluation of disease severity of RSV-infected plants. For compatibility, the coefficient values were adjusted so as to make the

TABLE 3. Evaluation of rice cultivars and lines for expression of symptoms of disease caused by rice stripe virus

\begin{tabular}{|c|c|c|c|c|c|c|c|c|c|}
\hline \multirow[b]{2}{*}{ Cultivar or line } & \multicolumn{6}{|c|}{$\begin{array}{l}\text { Number of seedlings } \\
\text { categorized by } \\
\text { symptoms }\end{array}$} & \multicolumn{3}{|c|}{ Disease index ${ }^{a}$} \\
\hline & A & B & $\mathrm{Bt}$ & $\mathrm{Cr}$ & $\mathrm{C}$ & $\mathrm{D}$ & DRI & SDI & SDI/DRI ratio \\
\hline Koshihikari & 15 & 9 & 4 & 3 & 4 & 4 & 68.7 & 68.2 & 0.99 \\
\hline NIL-STV2 & 2 & 3 & 0 & 4 & 4 & 26 & 20.8 & 19.1 & 0.92 \\
\hline NIL-STV11 & 13 & 9 & 2 & 2 & 6 & 3 & 67.3 & 67.4 & 1.00 \\
\hline NIL-STV2/STV11 & 0 & 2 & 2 & 2 & 1 & 33 & 13.6 & 11.5 & 0.84 \\
\hline Asahino-yume & 2 & 3 & 1 & 0 & 4 & 26 & 19.7 & 18.6 & 0.94 \\
\hline
\end{tabular}

${ }^{a}$ Disease rating index (DRI) and simple disease index (SDI) were calculated by equations 1 and 2, respectively, as described in the Materials and Methods. 
value of the SDI numerically similar to those of Washio's DRI. Recalculating disease severities of rice cultivars tested previously (Maeda et al. 2006) resulted in the SDI/DRI ratio ranging from 0.8 to 1.2, although a few cultivars with many D-rated plants had lower SDI values. A simulated data set generated to analyze the correspondence between DRI and SDI indicated a strong positive correlation between the two values (Pearson's correlation, $r=$ 0.9499, $P<0.0001)$. Good agreement was observed between equivalent DRI and SDI values (Lin's concordance correlation coefficient, $\rho_{c}=0.9329$, calculated using R 3.3.3 for MacOSX with DescTools v0.99.19) (Supplementary Fig. S3).

The Genetic Resources Center in Japan has more than 24,000 accessions of rice germplasm. Using these genetic resources, we have been seeking germplasm resistant to infection by RSV and have located 473 promising accessions, although the loci associated with the resistance have not yet been identified. Using the SDI in conjunction with QTL analysis should accelerate the evaluation of resistance to RSV in rice breeding programs.

\section{ACKNOWLEDGEMENTS}

We thank O. Ideta and H. Maeda for providing RSV-resistant rice seed.

\section{LITERATURE CITED}

Andersen, C. L., Jensen, J. L., and Orntoft, T. F. 2004. Normalization of realtime quantitative reverse transcription-PCR data: A model-based variance estimation approach to identify genes suited for normalization, applied to bladder and colon cancer data sets. Cancer Res. 64:5245-5250.

Cho, W. K., Lian, S., Kim, S. M., Park, S. H., and Kim, K. H. 2013. Current Insights into Research on Rice stripe virus. Plant Pathol. J. 29:223-233.

Fang, P., Lu, R., Sun, F., Lan, Y., Shen, W., Du, L., Zhou, Y., and Zhou, T. 2015. Assessment of reference gene stability in Rice stripe virus and Rice black streaked dwarf virus infection rice by quantitative real-time PCR. Virol. J. 12:175.

Hibino, H. 1990. Insect-borne viruses of rice. Adv. Dis. Vector Res. 6:209-241.

Hibino, H. 1996. Biology and epidemiology of rice viruses. Annu. Rev. Phytopathol. 34:249-274.

Ishii, M. 1971. Studies on the acquisition and transmission of rice stripe virus by the smaller brown planthopper, Laodelphax striatellus Fallen. I. Efficiency of virus acquisition under several feeding conditions. Bull. Chugoku Natl. Agric. Exp. Stn. 44:12-14 (in Japanese).

Izawa, T., Shumiya, A., Kudo, S., Kato, T., Fujii, K., Saka, N., Touyama, T., Sugiura, N., Ito, T., Kojima, H., and Nakajima, Y. 2001. A new variety "Asahinoyume". Res. Bull. Aichi Agric. Res. Cent. 33:1-10.

Kato, H. 2008. Development of rice varieties for whole crop silage (WCS) in Japan. JARQ 42:231-236.

Kim, B.-R., Nam, H.-Y., Kim, S.-U., Kim, S.-I., and Chang, Y.-J. 2003. Normalization of reverse transcription quantitative-PCR with housekeeping genes in rice. Biotechnol. Lett. 25:1869-1872.

Kim, J. S., Lee, G. S., Kim, C. S., Choi, H. S., Lee, S. H., Kim, M. K., Kwag, H. R., Nam, M., Kim, J. S., Noh, T. H., Kang, M. H., Cho, J. D., Kim, J. Y., Kang, H. J., Han, J. W., Kim, B. R., Jeong, S. S., Kim, J. H., Kuo, S. J., Lee, J. H., and Kim, T. S. 2011. Severe outbreak of rice stripe virus and its occurring factors. Korean J. Pestic. Sci. 15:545-572.

Kozera, B., and Rapacz, M. 2013. Reference genes in real-time PCR. J. Appl. Genet. 54:391-406.

Li, S., Li, X., Sun, L., and Zhou, Y. 2012. Analysis of rice stripe virus wholegene expression in rice and in the small brown planthopper by real-time quantitative PCR. Acta Virol. 56:75-79.

Li, S., Wang, H., and Zhou, G. 2014. Synergism between Southern rice blackstreaked dwarf virus and Rice ragged stunt virus enhances their insect vector acquisition. Phytopathology 104:794-799.

Livak, K. J., and Schmittgen, T. D. 2001. Analysis of relative gene expression data using real-time quantitative PCR and the $2^{-\triangle \triangle C T}$ method. Methods 25: 402-408.

Maeda, H., Matsushita, K., Iida, S., and Sunohara, Y. 2006. Characterization of two QTLs controlling resistance to rice stripe virus detected in a Japanese upland rice line, Kanto 72. Breed. Sci. 56:359-364.

Maeda, H., Sugisawa, T., Nemoto, H., and Sunohara, Y. 2004. QTL analysis for rice stripe resistance in the Japanese upland rice Kanto72. Breed. Sci. 54:19-26.
Noda, S., Omura, T., Murakami, M., and Tsuchizaki, T. 1991. Infection of rice viruses to the varieties resistant to Rice stripe virus. Ann. Phytopathol. Soc. Jpn. 57:259-262 (in Japanese with English abstract).

Okuda, M., Shiba, T., and Hirae, M. 2017. Quantitative analysis of Rice stripe virus in a transovarial transmission cycle during the development and reproduction of its vector, Laodelphax Striatellus. Virus Genes 53:898-905.

Pfaffl, W. M., Tichopad, A., Prgomet, C., and Neuvians, T. P. 2004. Determination of stable housekeeping genes, differentially regulated target genes and sample integrity: BestKeeper-Excel-based tool using pair-wise correlations. Biotechnol. Lett. 26:509-515.

Sanada-Morimura, S., Sakumoto, S., Ohtsu, R., Otuka, A., Huang, S.-H., Thanh, D. V., and Matsumura, M. 2011. Current status of insecticide resistance in the small brown planthopper, Laodelphax striatellus, in Japan, Taiwan, and Vietnam. Appl. Entomol. Zool. (Jpn.) 46:65-73.

Satoh, K., Kondoh, H., Sasaya, T., Shimizu, T., Choi, I. R., Omura, T., and Kikuchi, S. 2010. Selective modification of rice (Oryza sativa) gene expression by rice stripe virus infection. J. Gen. Virol. 91:294-305.

Shiba, T., Hirae, M., Hayano-Saito, Y., Ohto, Y., Uematsu, H., Sugiyama, A., and Okuda, M. 2018. Spread and yield loss mechanisms of rice stripe disease in rice paddies. Field Crops Res. 217:211-217.

Shiba, T., Hirae, M., Hayano-Saito, Y., Uematsu, H., Sasaya, T., Higuchi, H., Ohto, Y., and Okuda, M. 2016. Seasonal changes in the percentage of rice stripe virus viruliferous Laodelphax striatellus (Hemiptera: Delphacidae) in paddy fields in Japan. J. Econ. Entomol. 109:1041-1046.

Shimono, M., Sugano, S., Nakayama, A., Jiang, C.-J., Ono, K., Toki, S., and Takatsuji, H. 2007. Rice WRKY45 plays a crucial role in benzothiadiazoleinducible blast resistance. Plant Cell 19:2064-2076.

Shirako, Y., Falk, B. W., and Haenni, A.-L. 2011. Genus Tenuivirus. Page 771-776 in: Virus Taxonomy: Ninth Report of the International Committee on Taxonomy of Viruses. A. M. Q. King, M. J. Adams, E. J. Lefkowitz, and E. B. Carstens, eds. Elsevier, Academic Press, London.

Sonku, Y., and Sakurai, Y. 1973. Transmission of rice stripe virus by Laodelphax striatellus (Fallen) II. Translocation of the hopper-secreted virus and location of virus multiplication within a rice plant. Ann. Phytopathol. Soc. Jpn. 39:109-119 (in Japanese with English abstract).

Takahashi, Y., Omura, T., Shohara, K., and Tsuchizaki, T. 1987. Rapid and simplified ELISA for routine field inspection of rice stripe virus. Ann. Phytopathol. Soc. Jpn. 53:254-257.

Uehara-Ichiki, T., Shiba, T., Matsukura, K., Ueno, T., Hirae, M., and Sasaya, T. 2013. Detection and diagnosis of rice-infecting viruses. Front. Microbiol. 4:289.

Wang, B., Hajano, J.-U.-D., Ren, Y., Lu, C., and Wang, X. 2015. iTRAQ-based quantitative proteomics analysis of rice leaves infected by Rice stripe virus reveals several proteins involved in symptom formation. Virol. J. 12:99.

Wang, H. D., Chen, J. P., Zhang, H. M., Sun, X. L., Zhu, J. L., Wang, A. G., Sheng, W. X., and Adams, M. J. 2008. Recent Rice stripe virus epidemics in Zhejiang province, China, and experiments on sowing date, disease-yield loss relationships, and seedling susceptibility. Plant Dis. 92:1190-1196.

Washio, O., Ezuka, A., Sakurai, Y., and Toriyama, K. 1967. Studies on the breeding of rice varieties resistant to stripe disease: I. Varietal difference in resistance to stripe disease. Jpn. J. Breed. 17:91-98.

Xiong, R., Wu, J., Zhou, Y., and Zhou, X. 2008. Identification of a movement protein of the Tenuivirus rice stripe virus. J. Virol. 82:12304-12311.

Xiong, R., Wu, J., Zhou, Y., and Zhou, X. 2009. Characterization and subcellular localization of an RNA silencing suppressor encoded by Rice stripe tenuivirus. Virology 387:29-40.

Yamada, W., and Yamamoto, H. 1955. Studies on the stripe disease of rice plant III. Host plants, incubation period in the rice plant and retention and overwintering of the virus in the insect, Delphacodes striatella FALEN. Spec. Bull. Agric. Exp. Stn. Okayama Prefect. Gen. Agric. Cen. 52:35-56 (in Japanese with English abstract).

Yamamura, K., and Yokozawa, M. 2002. Prediction of a geographical shift in the prevalence of rice stripe virus disease transmitted by the small brown planthopper, Laodelphax striatellus (Fallen) (Hemiptera: Delphacidae), under global warming. Appl. Entomol. Zool. (Jpn.) 37:181-190.

Yoshida, K., Matsukura, K., Sakai, J., Onuki, M., Sanada-Morimura, S., Towata, T., and Matsumura, M. 2014. Seasonal occurrence of Laodelphax striatellus (Hemiptera: Delphacidae) in a rice-forage crops mixed cropping area in central Kyushu, Japan. Appl. Entomol. Zool. (Jpn.) 49:475-481.

Zhang, X., Wang, X. F., and Zhou, G. H. 2008. A one-step real time RT-PCR assay for quantifying rice stripe virus in rice and in the small brown planthopper (Laodelphax striatellus Fallen). J. Virol. Methods 151:181-187.

Zhang, Y. X., Jiang, L., Liu, L. L., Wang, B. X., Shen, Y. Y., Wang, Q., Cheng, X. N., and Wan, J. M. 2010. Quantitative trait loci associated with resistance to rice stripe virus and small brown planthopper infestation in rice. Crop Sci. 50:1854-1862.

Zhu, Y., Hayakawa, T., Toriyama, S., and Takahashi, M. 1991. Complete nucleotide sequence of RNA 3 of rice stripe virus: An ambisense coding strategy. J. Gen. Virol. 72:763-767. 